\title{
Parenchymal trafficking of pleural mesothelial cells in idiopathic pulmonary
}

\section{fibrosis}

\author{
K.K. Mubarak*, A. Montes-Worboys*, D. Regev*, N. Nasreen*,\#, K.A. Mohammed*,\#, \\ I. Faruqi*, E. Hensel*, M.A. Baz*, O.A. Akindipe*, S. Fernandez-Bussy*, \\ S.D. Nathan and V.B. Antony
}

ABSTRACT: Idiopathic pulmonary fibrosis (IPF) is characterised by myofibroblast proliferation leading to architectural destruction. Neither the origin nor the continued proliferation of myofibroblasts is well understood.

Explanted human IPF lungs were stained by immunohistochemistry for calretinin, a marker of pleural mesothelial cells (PMCs). Chronic obstructive pulmonary disease (COPD) and cystic fibrosis (CF) lungs acted as controls. The number of PMCs per 100 nucleated cells and per photomicrograph was estimated along with the Ashcroft score of fibrosis. Mouse PMCs expressing green fluorescent protein (GFP) or labelled with nanoparticles were injected into the pleural space of mice given intranasal transforming growth factor (TGF)- $\beta 1$. Mouse lungs were lavaged and examined for the presence of GFP, smooth muscle $\alpha$-actin ( $\alpha$-SMA) and calretinin.

Calretinin-positive PMCs were found throughout IPF lungs, but not in COPD or CF lungs. The number of PMCs correlated with the Ashcroft score. In mice, nanoparticle-laden PMCs were recoverable by bronchoalveolar lavage, depending on the TGF- $\beta 1$ dose. Fluorescent staining showed $\alpha$-SMA expression in GFP-expressing PMCs, with co-localisation of GFP and $\alpha$-SMA.

PMCs can traffic through the lung and show myofibroblast phenotypic markers. PMCs are present in IPF lungs, and their number correlates with IPF severity. Since IPF presumably begins subpleurally, PMCs could play a pathogenetic role via mesothelial-mesenchymal transition.

KEYWORDS: Cell trafficking, epithelial-mesenchymal transition, idiopathic pulmonary fibrosis, mesothelial-mesenchymal transition, pathogenesis, pleural mesothelial cells

diopathic pulmonary fibrosis (IPF) is a progressive lung disease characterised by cellular and structural changes in the parenchyma caused by proliferating myofibroblasts. For reasons that are not well understood, this process is thought to begin in the subpleural region, and then extend centrally. Proliferating myofibroblasts expressing smooth muscle $\alpha$-actin ( $\alpha$-SMA) are thought to be the key cells responsible for the pathological changes of IPF, which are characterised by increased deposition of extracellular matrix components, including collagen [1-3]. Neither the origin of these myofibroblasts nor the molecular mechanisms involved in their formation in the fibroblastic foci are clearly understood. A variety of sources have been postulated as origins for these myofibroblasts, including circulating progenitor cells [4] and resident mesenchymal cells $[1,4]$.

It is currently believed that the fibroblasts are derived, in part, from local tissues following the process of epithelial-mesenchymal transition (EMT) [5]. We have recently demonstrated in vitro that pleural mesothelial cells (PMCs) have the capacity to transition into a myofibroblast phenotype and undergo haptotactic migration in response to transforming growth factor (TGF)- $\beta 1$ [6]. We therefore hypothesised that such a process could also occur in vivo, leading to the characteristic findings seen on histopathology of IPF. This process can be denominated as "mesothelial-mesenchymal transition", a specialised form of EMT.

The pleural mesothelium is a metabolically active monolayer of cells that blankets the chest wall and lungs in parietal and visceral covers. During parenchymal inflammation, the PMCs are exposed to a microenvironment with high levels of cytokines, chemokines and growth factors, including TGF- $\beta 1$ [7-9]. TGF- $\beta 1$ is considered to be a master switch for the induction of fibrosis by a process of EMT in various organs, including the lung [10-13].
AFFILIATIONS

*Division of Pulmonary, Critical Care Medicine and Sleep Medicine, Dept of Medicine, College of Medicine, University of Florida, "Malcolm Randall VA Medical Center, Gainesville, FL,

"Advanced Lung Disease and Transplant Program, Inova Heart and Vascular Institute, Inova Fairfax Hospital, Falls Church, VA, and +Division of Pulmonary, Allergy and Critical Care Medicine, Depts of Medicine and Environmental Health Sciences, Birmingham, AL, USA.

CORRESPONDENCE

K.K. Mubarak

St Joseph Mercy Hospital

5333 McAuley Drive

Suite 3111

Ann Arbor

MI 48197

USA

E-mail: kamal.mubarak@gmail.com

Received:

Sept 022010

Accepted after revision:

May 152011

First published online:

July 072011

European Respiratory Journal Print ISSN 0903-1936 Online ISSN 1399-3003 
With stress or injury, PMCs attain plasticity, losing their polarity and mesothelial markers. The cellular transition of PMCs leads to cytoskeletal reorganisation, such that these cells acquire a spindle shape and express mesenchymal markers. The transformed PMCs lose the expression of adherens junctional proteins E-cadherin and $\mathrm{N}$-cadherin, as well as cytokeratin.

Because of its intimate proximity to the lung parenchyma, the pleura can respond to inflammatory cytokines released by exogenous inhaled agents in animals [14] as well as humans [15]. Thus, IPF may be a disease in which inhaled mediators cause parenchymal release of cytokines, such as TGF- $\beta 1$, leading to mesothelial activation, EMT and subsequent haptotaxis of activated myofibroblasts that form a cascading network of fibrosis, starting at the subpleural region and invaginating towards the hilum [16, 17].

Indeed, a recent study has shown that the hallmark lesion of IPF, the fibroblastic focus, is not a discrete site of epithelial injury and repair [18]. Instead, the fibroblastic foci seen on twodimensional histopathological sections are part of a complex and highly interconnected reticulum of polyclonal fibrous tissue that is reactive rather than malignant. Three-dimensional reconstruction showed that the leading edge of this invasion extends from the pleura to the underlying parenchyma.

Interestingly, in a mouse model of intrapleural bleomycin and carbon black co-administration, pleural fibrosis was demonstrated to extend into the parenchyma [19]. The subpleural distribution of fibrosis recapitulated the histopathology of IPF. The carbon particles were thought to be the "second hit," similar to cigarette smoke, that can, with the appropriate phenotype, predispose patients to IPF [20].

All of these findings suggest that pleural EMT can be a source of fibroblastic proliferation that invades the lung in IPF. Therefore, in our study, we hypothesised that PMCs traffic through IPF lungs while undergoing EMT leading to fibrosis. We also hypothesised that key elements of this paradigm that are difficult to study in human tissues can be recapitulated in a TGF- $\beta 1$ mouse model of pulmonary fibrosis, further validating our proposed pathogenetic mechanism.

\section{MATERIALS AND METHODS Explanted IPF lungs}

After informed consent was obtained, lungs of patients with IPF, chronic obstructive pulmonary disease (COPD), cystic fibrosis (CF) and idiopathic pulmonary arterial hypertension (IPAH) were preserved following lung transplantation at Inova Fairfax Hospital (Falls Church, VA, USA) and Shands Hospital at the University of Florida (Gainesville, FL, USA). One patient who underwent a pneumonectomy for haemorrhage from a broncholith was also included as a control. The specimens were fixed in formalin, embedded in paraffin and sectioned with a microtome before immunohistochemical staining on standard microscope slides. All biopsies were taken from the lower lobes and included the pleura and subjacent tissue.

\section{Immunohistochemistry for calretinin and mesothelin in human lungs}

Explanted lung slides were incubated with antibodies to calretinin (Cell Marque, Rocklin, CA, USA) and mesothelin (Invitrogen, Carlsbad, CA, USA) at dilutions of 1/500 and 1/100, respectively, for $30 \mathrm{~min}$ at room temperature before washing and incubation with a secondary biotinylated anti-mouse immunoglobulin G antibody (Vector Labs, Burlingame, CA, USA) for $30 \mathrm{~min}$ at room temperature. Colour was developed using VectaStain kit (Vector Labs) with VIP substrate, to give a magenta/pink colour, and diaminobenzidine (DAB), to give a brown colour. A light green counterstain was used to enhance the parenchyma with VIP and haematoxylin was used as a counterstain with DAB. The slides were visualised at $400 \times$ magnification. Any slides in which the pleura did not stain strongly for calretinin were rejected as inadequately stained and a new slide from the same tissue was stained. Fluorescence microscopy was also performed with these two antibodies, using Texas Red- and fluorescein isothiocyanate (FITC) (green)labelled secondary antibody staining, as described later.

\section{Calretinin-positive cell counts}

Two observers visualised each slide from explanted IPF lungs. The pleura was identified first so that the adequacy of calretinin staining could be confirmed. Five photomicrographs were then taken randomly, and the number of calretinin-positive cells per photomicrograph and the total number of nucleated cells were recorded.

\section{Ashcroft score}

For all IPF lungs, the Ashcroft fibrosis score [21] was assigned for each photomicrograph where calretinin-positive cells were counted. As with calretinin-positive cell counts, two observers determined the Ashcroft score.

\section{Clinical data}

After institutional review board approval, demographic data, pulmonary function tests, and details of the clinical course of IPF, COPD and CF patients were extracted from the electronic medical records at Inova Fairfax Hospital and Shands Hospital at the University of Florida.

\section{Green fluorescent protein-positive mouse mesothelial cells}

After approval from the institutional animal care committee, lungs of C57BL/6J mice (Jackson Laboratories, Bar Harbor, ME, USA) that constitutively express green fluorescent protein (GFP) were harvested following euthanasia. The mesothelial cells were extracted by trypsinisation, as we have previously described [22], and resuspended in Media-199 (Gibco Laboratories, Grand Island, NY, USA) containing 10\% fetal bovine serum (FBS) (Atlanta Biologicals, Lawrenceville, GA, USA), $100 \mathrm{U} \cdot \mathrm{mL}^{-1}$ penicillin and $100 \mu \mathrm{g} \cdot \mathrm{mL}^{-1}$ streptomycin (Cellgro; Mediatech, Herndon, VA, USA). The cells were plated in $75-\mathrm{cm}^{2}$ culture flasks (Corning Costar Corporation, Lowell, MA, USA) and incubated at $37^{\circ} \mathrm{C}$ in $5 \% \mathrm{CO}_{2}$ and $95 \%$ air. The medium was changed on alternate days or as needed.

\section{Mouse mesothelial cell culture}

Mouse mesothelial cells in primary culture were plated in 75$\mathrm{cm}^{2}$ culture flasks with F12K medium (Gibco Laboratories) supplemented with $10 \%$ heat-inactivated FBS, $100 \mathrm{U} \cdot \mathrm{mL}^{-1}$ penicillin, $100 \mu \mathrm{g} \cdot \mathrm{mL}^{-1}$ streptomycin, $1 \%$ amphotericin B (Gibco Laboratories), $1 \mathrm{mM}$ sodium pyruvate (Gibco Laboratories) and $10 \mathrm{mM}$ 4-(2-hydroxyethyl)-1-piperazine ethane sulfonic acid buffer (Sigma-Aldrich, St Louis, MO, USA). Cells were maintained 
at $37^{\circ} \mathrm{C}$ in a humidified atmosphere with $5 \% \mathrm{CO}_{2}$ and $95 \%$ air. The medium was changed on alternate days or as needed.

\section{Labelling mouse mesothelial cells with nanoparticles}

Mesothelial cells $\left(1 \times 10^{6}\right)$ from C57BL/6J mice were plated in $60-\mathrm{mm}$ dishes with serum-free F12K medium. Cells were incubated with silica nanoparticles coated with tetramethyl rhodamine isothiocyanate (TRITC) dye at $37^{\circ} \mathrm{C}$ in a humidified atmosphere with $5 \% \mathrm{CO}_{2}$ and $95 \%$ air for $24 \mathrm{~h}$. Silica nanoparticles are nontoxic to cultured cells [23, 24]. After incubation, cells were washed and centrifuged for $5 \mathrm{~min}$ at $400 \times g(1,500 \mathrm{rpm})$, and the pellet was resuspended in $200 \mu \mathrm{L}$ PBS to remove any free nanoparticles and injected into the pleural space of the mice using an Angiocath (Becton Dickinson, Franklin Lakes, NJ, USA), as previously described [25].

\section{TGF- $\beta 1$ mouse model}

Labelled or GFP-positive mouse mesothelial cells were injected into the pleural space of C57BL/6J mice using our previously described techniques [22]. Accidental injection into the lung parenchyma leads to bilateral pneumothorax and death, since the mouse has only one pleural cavity. TGF- $\beta 1$ (PeproTech, Rocky Hill, NJ, USA) was delivered nasally to the lungs at varying doses. Lungs were harvested after euthanasia at different time-points. The lungs were carefully examined and no injection injury was found in any lung.

\section{Mouse bronchoalveolar lavage, serum collection and tissue harvest}

Bronchoalveolar lavage (BAL) was performed at different time-points after intrapleural injection of TRITC-laden PMCs into mice given intranasal TGF- $\beta 1$ or saline. Fluid was collected by injecting $800-1,000 \mu \mathrm{L}$ Hank's balanced salt solution (HBSS) into the lungs via tracheal cannulation. The fluid was aspirated and the process was repeated until a total of 1,600-2,000 $\mu \mathrm{L} \mathrm{BAL}$ fluid was collected. BAL fluid was centrifuged at $400 \times g$ $(1,500 \mathrm{rpm})$ for $5 \mathrm{~min}$ to pellet the cells and separate the supernatant. BAL cells were analysed for fluorescence by reading the optical density at $541 \mathrm{~nm}$. The lungs were then perfused via the pulmonary artery with HBSS to clear the red blood cells. Optimal cutting temperature (OCT) compound $(800 \mu \mathrm{L})$ was injected into the lungs via tracheal cannulation to preserve lung architecture. Lungs were harvested and stored in OCT for frozen section analysis.

\section{Fluorescent microscopy}

After washing twice with PBS, frozen mouse lung tissue sections were fixed with $4 \%$ paraformaldehyde for $10 \mathrm{~min}$ at room temperature. The slides were incubated with anti- $\alpha-S M A$ rabbit anti-mouse antibody (Biocare, Concord, CA, USA) for $1 \mathrm{~h}$ and Texas Red goat anti-rabbit antibody (Invitrogen) for $30 \mathrm{~min}$. The nuclei were stained for 4',6-diamidino-2-phenylindole (Molecular Probes, Eugene, OR, USA) for $10 \mathrm{~min}$ in the dark. The sections were then washed twice with PBS and the cover slide was mounted using the SlowFade Antifade kit (Molecular Probes). The GFP and Texas Red signals were analysed in each tissue using a specific filter on a fluorescent microscope (Zeiss LSM 510 Axiovert 200M; Zeiss, Thornwood, NY, USA).

\section{Statistical analysis}

Data analyses were performed by using Excel 12.2 software (Microsoft, Redmond, WA, USA).

\section{RESULTS}

\section{Demographic characteristics of the study group}

28 patients were included in the study. Their ages ranged from 8 to $71 \mathrm{yrs}$. All of the patients underwent lung transplantation between 2006 and 2009. 16 patients were diagnosed with IPF, eight patients with COPD, two patients with CF and one patient with IPAH. Tissue from one patient who suffered from severe haemorrhage due to a broncholith and required a pneumonectomy was also included. Diagnoses were made based upon generally accepted criteria for each disease. Table 1 shows the characteristics of the human subjects included in this study.

\section{Calretinin-positive cells correlate with the degree of fibrosis in human lung tissue}

We stained IPF human lung sections for calretinin and obtained five photomicrographs for each specimen. The calretinin-positive cells were found predominantly in the areas of interstitial fibrosis. Rarely, they could also be seen in and around bronchioli. Two observers estimated the Ashcroft score of the degree of fibrosis, the number of calretinin-positive cells and the total number of nucleated cells in each photomicrograph. In cases where there was minor disagreement between the two observers, the Ashcroft score and/or the number of calretinin-positive cells were averaged. If the disagreement in the number of calretinin-positive cells was $>15 \%$, the cells were counted again. Altogether, each observer counted $>40,000$ nucleated cells.

We found a significant positive correlation between the number of calretinin-positive cells and the degree of fibrosis in a given photomicrograph (fig. 1a). We also found that the number of calretinin-positive cells per 100 nucleated cells correlated with the Ashcroft score for that patient (fig. 1b).

\section{Immunohistochemistry for calretinin in human lung tissue}

Figure 2 shows the positive calretinin staining of mesothelial cells in the fibrotic lungs from patients with IPF. The pleura stained intensely (pink), indicating the presence of calretinin (fig. 2a). When the parenchyma was stained, calretinin-positive cells were found throughout the parenchyma (fig. 2b). When the lung samples from patients with COPD were analysed, only

\begin{tabular}{lccc} 
TABLE 1 & $\begin{array}{l}\text { Demographics characteristics of the study } \\
\text { population }\end{array}$ \\
Aetiology & Patients & Mean age yrs & Males \% \\
\hline IPF & 16 & 61 & 88 \\
COPD & 8 & 58 & 38 \\
CF & 2 & 23 & 50 \\
IPAH & 1 & 8 & 0 \\
Normal & 1 & 48 & 0 \\
\hline
\end{tabular}

The normal lung tissue was taken from a patient who suffered severe haemorrhage from a broncholith requiring a pneumonectomy. IPF: idiopathic pulmonary fibrosis; COPD: chronic obstructive pulmonary disease; CF: cystic fibrosis; IPAH: idiopathic pulmonary arterial hypertension. 


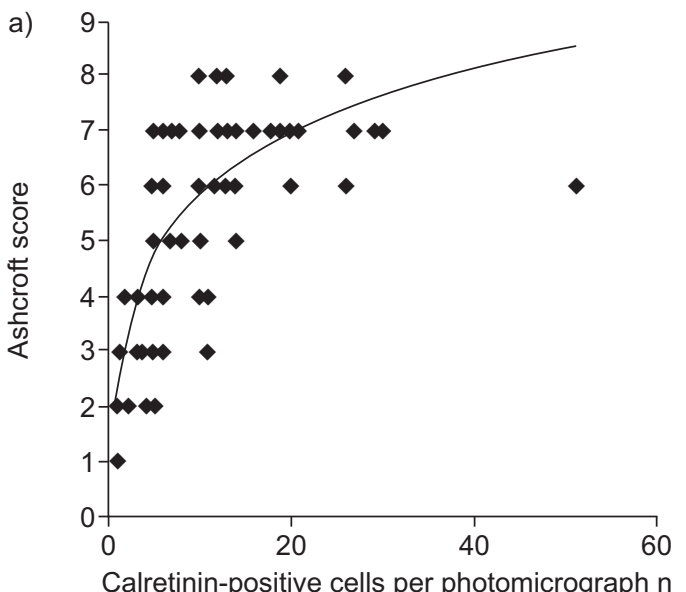

b)

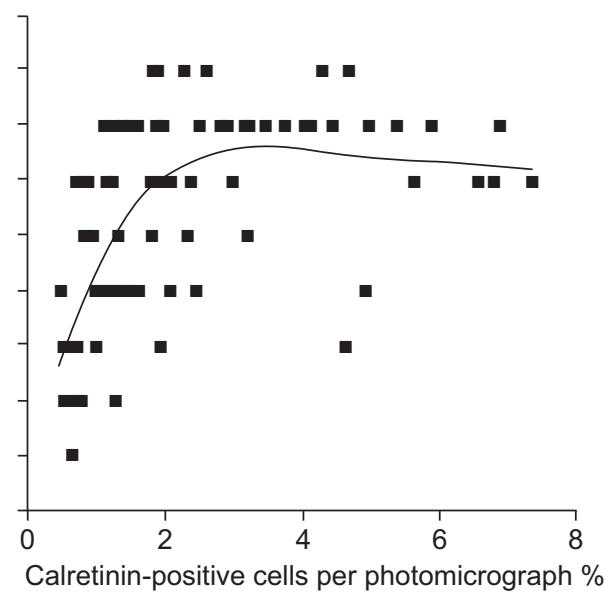

FIGURE 1. For each individual lung specimen stained for calretinin, 10 photomicrographs were taken ( $400 \times$ magnification). a) The number of calretinin-positive cells for each photomicrograph was correlated with the Ashcroft score of that micrograph $\left(r^{2}=0.52713, p<0.0001\right)$. b) The total number of nucleated cells per photomicrograph was also counted and then the percentage of calretinin-positive cells was correlated with the Ashcroft score $\left(r^{2}=0.40295, p<0.0001\right)$.

rare calretinin-positive cells were noted in emphysematous lung tissue. Similarly, only rare calretinin-positive cells were noted in $\mathrm{CF}$, IPAH and normal lung tissue.

\section{Immunohistochemistry for mesothelin in human lung tissue} Calretinin is only $95 \%$ sensitive and $86 \%$ specific for cells of mesothelial origin [26]. To confirm that the cells detected by calretinin staining were of mesothelial origin, a second stain, mesothelin, was employed. Mesothelin is 73\% sensitive and $55 \%$ specific for the mesothelium [26], but combined with calretinin, further increases the sensitivity and specificity for cells of pleural origin. Consecutive microtome sections were obtained from IPF lungs. Adjacent sections were stained with calretinin and mesothelin using exactly the same reagents, concentrations and incubation times. The same clusters of cells that stained positively for calretinin (fig. 3a and c) also stained for mesothelin (fig. $3 b$ and d).

\section{Fluorescence microscopy for calretinin and mesothelin in human lung tissue}

Figure $3 \mathrm{e}-\mathrm{h}$ show that IPF lungs, when stained for calretinin, demonstrated positivity in the parenchyma (Texas Red). Furthermore, when the same section was stained for mesothelin (FITC), the same cells show positivity for mesothelin. The
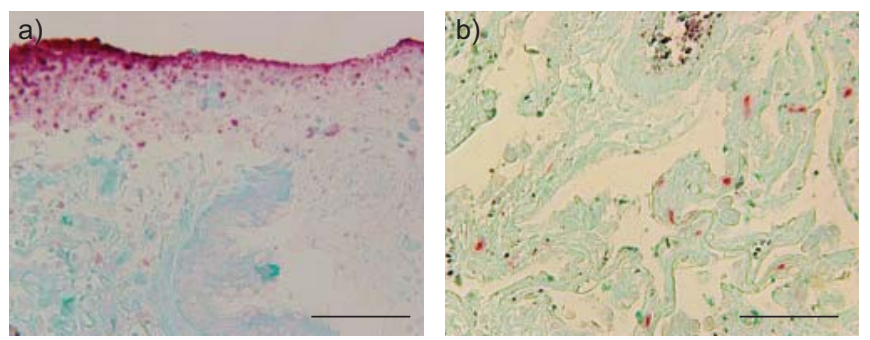

FIGURE 2. Calretinin staining of explanted human lungs. a) In an explanted lung from a patient with idiopathic pulmonary fibrosis (IPF), the pleural surface shows intense calretinin staining. However, calretinin-positive cells can also be seen subpleurally. b) Calretinin-positive cells can also be seen in the parenchyma of IPF lungs, albeit in lesser numbers. Scale bars $=50 \mu \mathrm{m}$. concordance of staining was not $100 \%$, as would be expected from mesothelial markers that have different sensitivities and specificities for mesothelial origin.

\section{Mouse mesothelial cells laden with TRITC nanoparticles were present in the BAL fluid of TGF-ק1-treated mice}

Figure $4 \mathrm{a}$ shows the increase of fluorescence in a dose- and time-dependent manner in BAL from TGF- $\beta 1$-treated mice compared with saline control mice. The results represent the mean of three mice for each group. Figure $4 \mathrm{~b}$ and $\mathrm{c}$ shows fluorescence imaging of BAL fluid from TGF- $\beta 1$ - and salinetreated mice. The BAL fluid from mice treated with $1.5 \mathrm{ng}$ TGF- $\beta 1$ contained nanoparticles at $24 \mathrm{~h}$ while the fluid from saline control mice did not. Figure $4 \mathrm{~d}-\mathrm{f}$ demonstrates fluorescence imaging of lung histopathology. The nanoparticles were found inside the parenchyma with $1.5 \mathrm{ng}$ TGF- $\beta 1$ at $12 \mathrm{~h}$ (fig. 4e), while none were seen with saline (fig. 4d). Even at $48 \mathrm{~h}$, the nanoparticles remained at the pleural surface with saline (fig. 4f). Together, these data indicate that these cells, when injected into the pleural space, migrate though the parenchyma, under the influence of TGF- $\beta 1$.

\section{GFP-expressing mouse mesothelial cells migrate into the lung parenchyma in TGF- $\beta 1$-treated mice}

To further confirm the results with nanoparticle-laden mesothelial cells found in the BAL in TGF- $\beta 1$-inoculated mice, we repeated the same experiment but injected GFP-expressing mesothelial cells into the pleural space of TGF- $\beta 1$ or saline pre-treated mice. Figure 5 shows a GFP-positive signal inside the lung parenchyma of mice treated with TGF- $\beta 1$ as compared with saline-inoculated mice. This indicated the migration of GFP-expressing mesothelial cells from the pleural space to the parenchyma when mice were treated with TGF- $\beta 1$. Furthermore, when stained with Texas Red for the presence of $\alpha$-SMA, the GFP-labelled cells demonstrated a yellow colour, indicating that the GFP-labelled PMCs had begun to express $\alpha$-SMA.

\section{DISCUSSION}

In this study, we demonstrated the presence of calretininpositive cells in explanted lung tissue in IPF. This phenomenon 

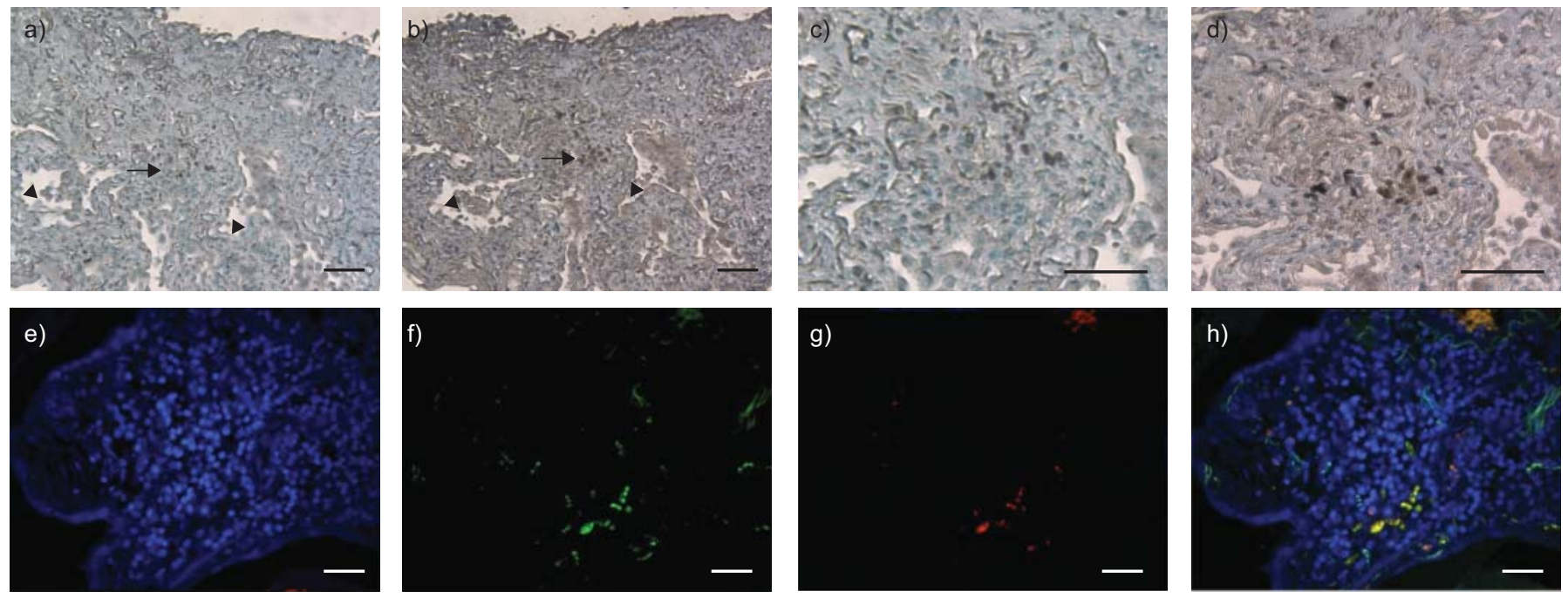

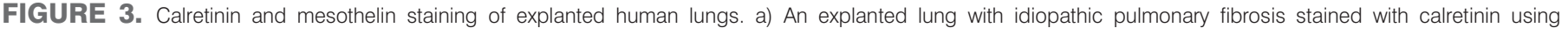

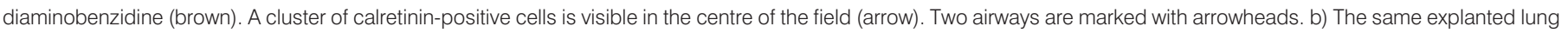

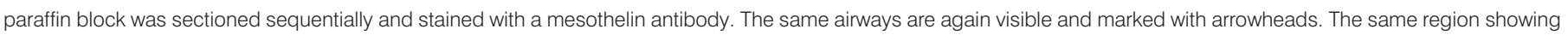

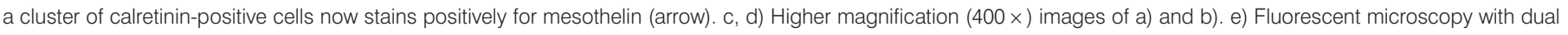

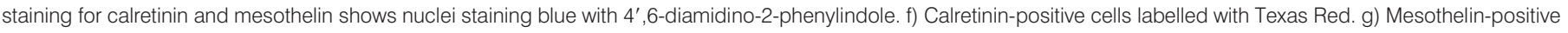

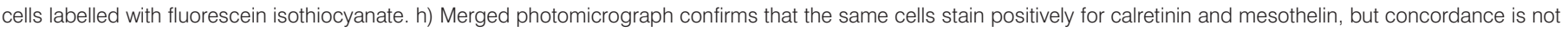
$100 \%$ given different sensitivities and specificities of these stains for mesothelial origin. Scale bars $=50 \mu \mathrm{m}$.

appeared to be specific to patients with IPF, since we observed only rare calretinin-positive cells in normal lung tissue, emphysematous lung tissue and CF lung tissue. Just as leukocytes gravitate to areas of infection and inflammation via chemotaxis, these PMCs appeared to be attracted to areas of fibrosis.

We were able to demonstrate a correlation between the number of calretinin-positive cells and the degree of fibrotic change in the parenchyma, as measured by the Ashcroft score. Whether the number of calretinin-positive cells was measured as a raw number or as percentage of the total nucleated cells seen in a photomicrograph, the correlation with the degree of fibrosis was highly significant. The Ashcroft score was originally described in 1988, but over more than $20 \mathrm{yrs}$, it has remained the best and most enduring score for histopathological grading of pulmonary fibrosis [27-32]. The scale starts at 0 , which indicates a normal lung; a score of 1 represents minimal fibrosis, 3 represents minimal fibrosis with preserved architecture, 5 indicates definite distortion with fibrous bands, 7 denotes severe distortion with honeycomb change and 8 connotes total fibrous obliteration.

The fact that these cells could originate from the pleural surface, invading the lung parenchyma, is borne out by our TGF- $\beta 1$ mouse model. This process was dose- as well as time-dependent. Whether we looked at PMCs labelled with GFP or nanoparticles, these cells invade the lung parenchyma in response to TGF- $\beta 1$, a well-known growth factor that induces fibrosis in murine models.

This work is a follow-up study to our recent article showing haptotactic migration of PMCs in vitro [6]. When cultured PMCs were exposed to a profibrotic stimulus, such as TGF- $\beta 1$, they underwent EMT in a Smad2-dependent manner. The phenotype of these cells changed to a fibroblastic morphology with simultaneous expression of $\alpha$-SMA, fibroblast specific protein-1, and collagen type I. This transition was accompanied by migration of these cells along the TGF- $\beta 1$ gradient.

There are important differences between the murine and human pleura. In mice, the mesothelial layer lies in close proximity to the parenchyma, but in humans, it has subjacent vasculature and stroma. Thus, mesothelial trafficking in the human condition needs to overcome more anatomical barriers than the murine situation. Therefore, extrapolation of results from the mouse to human must be done with caution.

Traditionally, PMCs have been thought to remain relatively quiescent on the opposing surfaces of the lung and chest wall. Their primary purpose has been thought to be production of a lubricating layer of pleural fluid to facilitate expansion of the lung by reducing friction with the encasing musculoskeletal structures of the thorax. Their role in host defence and fighting infections, such as empyema, has also been well recognised [33]. However, despite the proximity to the pulmonary parenchyma, and despite subpleural patterns seen in several lung diseases, the pleura has been thought to be an innocent bystander in parenchymal disease. Pleural plaques from asbestos lung disease and empyema from parenchymal infections have been congruent with this notion that the parenchyma can affect the pleura, but not vice versa. Our study supports the notion that the reverse may also hold true. Therefore, we speculate that in IPF, this metabolically active layer of cells may be more pathophysiologically important than previously thought.

IPF is also characterised by basal predominance. However, there is increasing evidence that genetic mutations may be responsible for the absence of the apicobasal gradient [34-36]. Our study did not address this phenomenon since all the biopsy specimens were taken from the lower lobes, nor did we attempt to look for such mutations. 

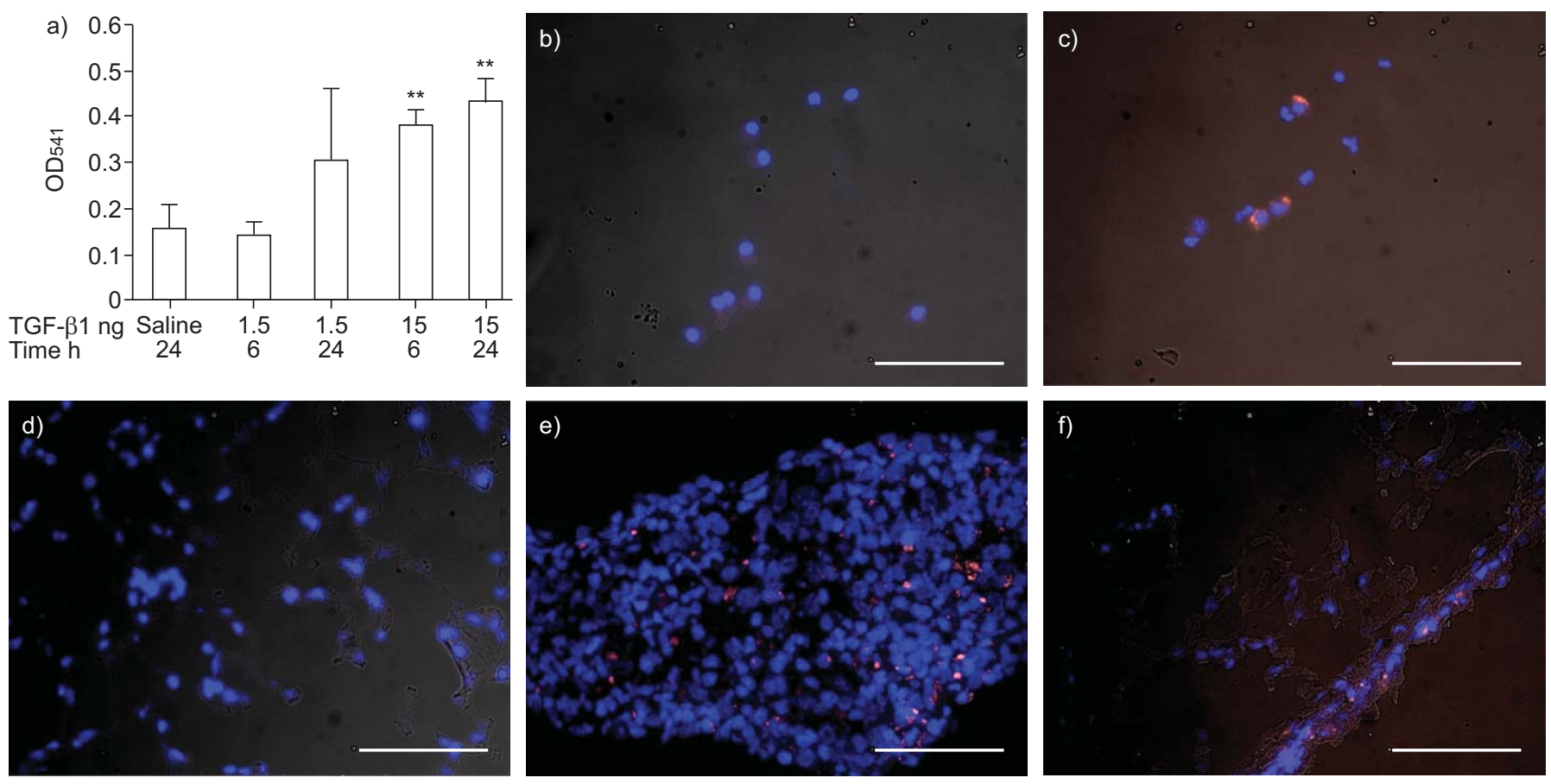

FIGURE 4. Mice injected intrapleurally with nanoparticle-labelled pleural mesothelial cells (PMCs) and then administered intranasal transforming growth factor (TGF)- $\beta 1$ demonstrated migration of PMCs into lung parenchyma in a dose- and time-dependent manner. a) The higher the dose of TGF- $\beta 1$, the more nanoparticle-laden cells were recovered by bronchoalveolar lavage (BAL). The number of cells recovered by BAL increased over time, peaking at $24 \mathrm{~h}$. Optical density was measured at $541 \mathrm{~nm}$ (OD541) in BAL cells to quantify the presence of fluorescence signal. $n=3$. **: $p<0.01$ compared with saline at $24 \mathrm{~h}$. b) BAL cells from saline-injected mice at $24 \mathrm{~h}$. Blue colour indicates nuclei stained with 4',6-diamidino-2-phenylindole (DAPI). c) BAL cells from mice treated with $1.5 \mathrm{ng}$ TGF- $\beta 1$ at $24 \mathrm{~h}$. Blue colour indicates nuclei stained with DAPI and red colour represents the nanoparticles coated with tetramethyl rhodamine isothiocyanate. d) Lung tissue from control mouse at $12 \mathrm{~h}$. e) Lung tissue from mouse treated with $1.5 \mathrm{ng}$ TGF- $\beta 1$ at $12 \mathrm{~h}$. f) Lung tissue from saline control at $48 \mathrm{~h}$ showing that the nanoparticles were still at the pleural surface. Scale bars $=50 \mu \mathrm{m}$.
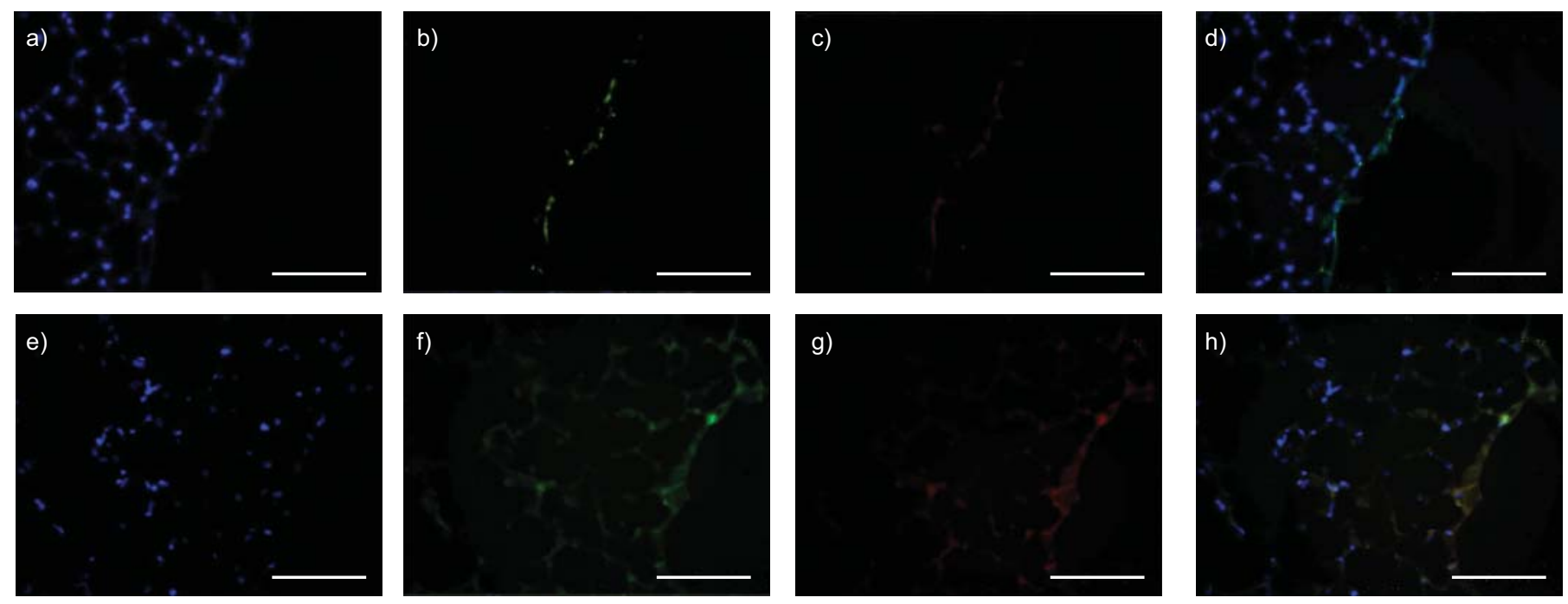

FIGURE 5. Mice injected intrapleurally with green fluorescent protein (GFP)-expressing pleural mesothelial cells (PMCs) and given intranasal transforming growth factor (TGF)- $\beta 1$ demonstrated that GFP-expressing PMCs invaded the lung parenchyma and expressed smooth muscle $\alpha$-actin $\left(\alpha\right.$-SMA). $n=3$. a) Saline control imaged with $4^{\prime}, 6-$ diamidino-2-phenylindole (DAPI) fluorescence showing the presence of nuclei in the parenchyma and pleura. b) Saline control imaged for GFP showing the presence of GFPexpressing PMCs on the pleural surface. c) Saline control imaged with Texas Red fluorescence showing very faint $\alpha$-SMA in the pleura. d) Merged image of parts a-c showing no $\alpha$-SMA in GFP-expressing PMCs. e) TGF- $\beta 1$ mouse imaged for DAPI fluorescence. f) TGF- $\beta 1$ mouse showing GFP-expressing PMCs on the pleural surface and at least one in the parenchyma. Many more fluorescent PMCs adhered to the surface. g) Texas Red fluorescence showing $\alpha$-SMA expression in the pleura. h) Merged image of parts e-g showing that PMCs expressed $\alpha$-SMA in the TGF- $\beta 1$-treated mice. Scale bars $=50 \mu \mathrm{m}$. 
Interestingly, there have been hints in the literature that mesothelial cells are not stationary, and are far more responsive to the local microenvironment than once believed. PMCs can traffic through the lung parenchyma and appear in mediastinal lymph nodes [37]. Mesothelioma can be misdiagnosed as metastatic when, in fact, it is localised [38]. A similar process has been noted in the peritoneum. Ovarian carcinoma can be misdiagnosed as metastatic because of the presence of peritoneal mesothelial cells in pelvic lymph nodes [39-41]. Therefore, it is quite likely that PMCs traffic through the lungs under pathological conditions, and perhaps at a slower rate under physiological conditions.

Our work builds upon the seminal work of DECOLOGNE et al. [42], who demonstrated congruent findings in a different model of fibrosis. While our model has used inhaled TGF- $\beta 1$, DECOLOGNE et al. [42] used adenovirally mediated transient TGF- $\beta 1$ expression in the pleural mesothelium, leading to pleural fibrosis but no pleurodesis. There was subpleural fibrosis in the parenchyma via EMT, but none in the chest wall. Since we believe that an inhaled stimulus is more likely to cause IPF than a pleural infection, we chose to deliver TGF- $\beta 1$ via inhalation in our model and correlate that with histopathology of human IPF. However, our model has an important limitation in that it is a short-term model that is unable to quantify the development of fibrosis, such as using a hydroxyproline assay.

Recent evidence has shown that the pleural surface reacts to inhaled antigens very quickly. Inhaled ovalbumin produces pleural oedema detectable by magnetic resonance imaging and histopathology within $3 \mathrm{~h}$. Thus, it is quite possible that environmental agents can provoke a cascade of pleural inflammation that initiates a wave of fibrosis caused by trafficking PMCs, which undergo EMT as they transform normal parenchyma into honeycomb lung in a centripetal fashion.

Pulmonary fibrosis caused by asbestos may share certain similarities with the foregoing hypothesis. Asbestos lung disease can manifest decades after the original exposure, with the particles slowly migrating from the parenchyma to the pleura [43]. In many instances, the fibres may no longer be detectable, presumably being catabolised by macrophages or tissue enzymes [44]. However, even in such cases, the changes brought about by asbestos can eventually lead to mesothelioma, presumably by chronic parenchymal activation or inflammation. Therefore, the pleura and the parenchyma can interact to produce pathology in multiple lung conditions, and IPF may be only one such clinical paradigm.

Our findings raise the question as to whether or not dysregulated PMCs can cause IPF. It does appear that our data meet at least some of the criteria for causality [45]. These include the finding that the presence of mesothelial cells in lung parenchyma is relatively specific to IPF, and does not seem to occur in COPD or CF. We counted a higher number of PMCs in areas that had higher grades of fibrosis. Moreover, the PMCs made up a higher percentage of cells in areas with higher grade of fibrosis. Thus the strength of association between the geographic heterogeneity of fibrosis and the number of mesothelial cells suggests that a dose-response relationship could exist. This is further supported by the dose-response relationship in our mouse models of TGF- $\beta 1$ and pulmonary fibrosis. Given the findings of EMT in mesothelial cells in vitro, it appears biologically plausible that mesothelial cells could transition into myofibroblasts in vivo.

Although it is possible, and indeed likely, that other cell lineages contribute to fibrosis via EMT, the notion that pleural EMT may cause or contribute to fibrosis is reasoned and consistent with the natural history and biology of the disease. Specifically, the disease is known to start subpleurally and progress into the parenchyma, suggesting a centripetal invading wave of fibrosis that is accompanied by clinical worsening. Further supportive experimental evidence will be required, including the use of selective knock-in mice that permanently mark adult cell lineages, such as PMCs. Nonetheless, our findings provide preliminary evidence that the pleural surface may not be an innocent bystander in the pathogenesis of this deadly disease.

\section{SUPPORT STATEMENT}

This work was supported by National Institutes of Health grants R21AA014796 and R01AI080349 to V.B. Antony.

\section{STATEMENT OF INTEREST}

None declared.

\section{ACKNOWLEDGEMENTS}

We would like to acknowledge the kindness of C. McCall. Secretarial support was provided by C. Dämm, P. Perry and L. Owens (University of Florida, Gainesville, FL, USA).

\section{REFERENCES}

1 Kalluri R, Neilson EG. Epithelial-mesenchymal transition and its implications for fibrosis. J Clin Invest 2003; 112: 1776-1784.

2 Neilson EG, Plieth D, Venkov C. Epithelial-mesenchymal transitions and the intersecting cell fate of fibroblasts and metastatic cancer cells. Trans Am Clin Climatol Assoc 2003; 114: 87-100.

3 Noble PW. Idiopathic pulmonary fibrosis. New insights into classification and pathogenesis usher in a new era therapeutic approaches. Am J Respir Cell Mol Biol 2003; 29: Suppl. 3, S27-S31.

4 Abe R, Donnelly SC, Peng T, et al. Peripheral blood fibrocytes: differentiation pathway and migration to wound sites. J Immunol 2001; 166: 7556-7562.

5 Iwano M, Plieth D, Danoff TM, et al. Evidence that fibroblasts derive from epithelium during tissue fibrosis. J Clin Invest 2002; 110: 341-350.

6 Nasreen N, Mohammed KA, Mubarak KK, et al. Pleural mesothelial cell transformation into myofibroblasts and haptotactic migration in response to TGF- $\beta 1$ in vitro. Am J Physiol Lung Cell Mol Physiol 2009; 297: L115-L124.

7 Strutz F, Zeisberg M, Ziyadeh FN, et al. Role of basic fibroblast growth factor-2 in epithelial-mesenchymal transformation. Kidney Int 2002; 61: 1714-1728.

8 Pochetuhen K, Luzina IG, Lockatell V, et al. Complex regulation of pulmonary inflammation and fibrosis by CCL18. Am J Pathol 2007; 171: 428-437.

9 Broekelmann TJ, Limper AH, Colby TV, et al. Transforming growth factor $\beta_{1}$ is present at sites of extracellular matrix gene expression in human pulmonary fibrosis. Proc Natl Acad Sci USA 1991; 88: 6642-6646.

10 Willis BC, du Bois RM, Borok Z. Epithelial origin of myofibroblasts during fibrosis in the lung. Proc Am Thorac Soc 2006; 3: 377-382.

11 Zeisberg M, Kalluri R. The role of epithelial-to-mesenchymal transition in renal fibrosis. J Mol Med 2004; 82: 175-181.

12 Friedman SL. Molecular regulation of hepatic fibrosis, an integrated cellular response to tissue injury. J Biol Chem 2000; 275: 2247-2250. 
13 Verrecchia F, Mauviel A. Transforming growth factor- $\beta$ and fibrosis. World J Gastroenterol 2007; 13: 3056-3062.

14 Quintana HK, Cannet C, Schaeublin E, et al. Identification with MRI of the pleura as a major site of the acute inflammatory effects induced by ovalbumin and endotoxin challenge in the airways of the rat. Am J Physiol Lung Cell Mol Physiol 2006; 291: L651-L657.

15 Song Y, Li X, Du X. Exposure to nanoparticles is related to pleural effusion, pulmonary fibrosis and granuloma. Eur Respir J 2009; 34: 559-567.

16 Antony VB. Immunological mechanisms in pleural disease. Eur Respir J 2003; 21: 539-544.

17 Quintana HK, Cannet C, Schaeublin E, et al. Identification with MRI of the pleura as a major site of the acute inflammatory effects induced by ovalbumin and endotoxin challenge in the airways of the rat. Am J Physiol Lung Cell Mol Physiol 2006; 291: L651-L657.

18 Cool CD, Groshong SD, Rai PR, et al. Fibroblast foci are not discrete sites of lung injury or repair: the fibroblast reticulum. Am J Respir Crit Care Med 2006; 174: 654-658.

19 Decologne N, Wettstein G, Kolb M, et al. Bleomycin induces pleural and subpleural fibrosis in the presence of carbon particles. Eur Respir J 2010; 35: 176-185.

20 Baumgartner KB, Samet JM, Stidley CA, et al. Cigarette smoking: a risk factor for idiopathic pulmonary fibrosis. Am J Respir Crit Care Med 1997; 155: 242-248.

21 Ashcroft T, Simpson JM, Timbrell V. Simple method of estimating severity of pulmonary fibrosis on a numerical scale. J Clin Pathol 1988; 41: 467-470.

22 Mohammed KA, Nasreen N, Ward MJ, et al. Helper T cell type 1 and 2 cytokines regulate $\mathrm{C}-\mathrm{C}$ chemokine expression in mouse pleural mesothelial cells. Am J Respir Crit Care Med 1999; 159: 1653-1659.

23 Faisal M, Hong Y, Liu J, et al. Fabrication of fluorescent silica nanoparticles hybridized with AIE luminogens and exploration of their applications as nanobiosensors in intracellular imaging. Chemistry 2010; 16: 4266-4272.

24 Yang $\mathrm{H}, \mathrm{Wu} \mathrm{Q}$, Tang $\mathrm{M}$, et al. In vitro study of silica nanoparticleinduced cytotoxicity based on real-time cell electronic sensing system. J Nanosci Nanotechnol 2010; 10: 561-568.

25 Mohammed KA, Nasreen N, Ward MJ, et al. Induction of acute pleural inflammation by Staphylococcus aureus. I. CD4+ T cells play a critical role in experimental empyema. J Infect Dis 2000; 181: 1693-1699.

26 Kachali C, Eltoum I, Horton D, et al. Use of mesothelin as a marker for mesothelial cells in cytologic specimens. Semin Diagn Pathol 2006; 23: 20-24.

27 Hagiwara SI, Ishii $Y$, Kitamura S. Aerosolized administration of $N$ acetylcysteine attenuates lung fibrosis induced by bleomycin in mice. Am J Respir Crit Care Med 2000; 162: 225-231.

28 Matsuoka H, Arai T, Mori M, et al. A p38 MAPK inhibitor, FR167653, ameliorates murine bleomycin-induced pulmonary fibrosis. Am J Physiol Lung Cell Mol Physiol 2002; 283: L103-L112.

29 Simler NR, Howell DC, Marshall RP, et al. The rapamycin analogue SDZ RAD attenuates bleomycin-induced pulmonary fibrosis in rats. Eur Respir J 2002; 19: 1124-1127.
30 Murakami S, Nagaya N, Itoh T, et al. Prostacyclin agonist with thromboxane synthase inhibitory activity (ONO-1301) attenuates bleomycin-induced pulmonary fibrosis in mice. Am J Physiol Lung Cell Mol Physiol 2006; 290: L59-L65.

31 Murakami S, Nagaya N, Itoh T, et al. C-type natriuretic peptide attenuates bleomycin-induced pulmonary fibrosis in mice. Am J Physiol Lung Cell Mol Physiol 2004; 287: L1172-L1177.

32 Izumo T, Kondo M, Nagai A. Cysteinyl-leukotriene 1 receptor antagonist attenuates bleomycin-induced pulmonary fibrosis in mice. Life Sci 2007; 80: 1882-1886.

33 Jantz MA, Antony VB. Pathophysiology of the pleura. Respiration 2008; 75: 121-133.

34 Lawson WE, Crossno PF, Polosukhin VV, et al. Endoplasmic reticulum stress in alveolar epithelial cells is prominent in IPF: association with altered surfactant protein processing and herpesvirus infection. Am J Physiol Lung Cell Mol Physiol 2008; 294: L1119L1126.

35 Lawson WE, Grant SW, Ambrosini V, et al. Genetic mutations in surfactant protein $\mathrm{C}$ are a rare cause of sporadic cases of IPF. Thorax 2004; 59: 977-980.

36 Kottmann RM, Hogan CM, Phipps RP, et al. Determinants of initiation and progression of idiopathic pulmonary fibrosis. Respirology 2009; 14: 917-933.

37 Brooks JS, LiVolsi VA, Pietra GG. Mesothelial cell inclusions in mediastinal lymph nodes mimicking metastatic carcinoma. Am J Clin Pathol 1990; 93: 741-748.

38 Argani P, Rosai J. Hyperplastic mesothelial cells in lymph nodes: report of six cases of a benign process that can stimulate metastatic involvement by mesothelioma or carcinoma. Hum Pathol 1998; 29: 339-346.

39 Alvarado Cabrero I, Sosa Romero A. Inclusiones epiteliales benignas en ganglios linfaticos pelvicos. Informe de does casos [Benign epithelial inclusions in pelvic lymph nodes. 2 case reports]. Ginecol Obstet Mex 2000; 68: 77-81.

40 Kir G, Eren S, Kir M. Hyperplastic mesothelial cells in pelvic and abdominal lymph node sinuses mimicking metastatic ovarian microinvasive serous borderline tumour. Eur J Gynaecol Oncol 2004; 25: 236-238.

41 Clement PB, Young RH, Oliva E, et al. Hyperplastic mesothelial cells within abdominal lymph nodes: mimic of metastatic ovarian carcinoma and serous borderline tumour - a report of two cases associated with ovarian neoplasms. Mod Pathol 1996; 9: 879-886.

42 Decologne N, Kolb M, Margetts PJ, et al. TGF- $\beta 1$ induces progressive pleural scarring and subpleural fibrosis. J Immunol 2007; 179: 6043-6051.

43 Beattie J, Knox JF. Studies of mineral content and particle size distribution in the lungs of asbestos textile workers. In: Davis CN, ed. Inhaled Particles and Vapours. London, Pergamon Press, 1961; pp. 419-432.

44 Nagelschmidt G. Some observations of the dust content and composition in lungs with asbestosis, made during work on coal miners pneumoconiosis. Ann NY Acad Sci 1965; 132: 64-76.

45 Hill $\mathrm{AB}$. The environment and disease: association or causation? Proc R Soc Med 1965; 58: 295-300. 